\title{
Trends in parasite prevalence following 13 years of malaria interventions on Bioko island, Equatorial Guinea: 2004-2016
}

\author{
Jackie Cook ${ }^{*} \mathbb{D}$, Dianna Hergott ${ }^{2}$, Wonder Phiri ${ }^{3}$, Matilde Riloha Rivas ${ }^{4}$, John Bradley ${ }^{1}$, Luis Segura ${ }^{3}$, \\ Guillermo Garcia ${ }^{2}$, Chris Schwabe ${ }^{2}$ and Immo Kleinschmidt ${ }^{1,5}$
}

\begin{abstract}
Background: Whilst there have been substantial reductions in malaria transmission over the past decade, in many countries in West and Central Africa the malaria burden remains high. Monitoring and evaluation of malaria transmission trends and intervention strategies are key elements for malaria control programmes. This study uses a time series of annual malaria indicator surveys to track the progress of malaria control in Bioko Island, Equatorial Guinea, over a 13 year period of intensive interventions. Malaria infection and haemoglobin were measured annually in children (1 to 14 years) in cross-sectional household surveys from 2004 to 2016 in 18 sentinel sites across the island. Trends in transmission patterns were assessed and the impact of the vector control interventions (net use and spray coverage) was evaluated.
\end{abstract}

Results: Between 2004 and 2016 approximately 106,500 individual tests for parasitaemia were conducted using rapid diagnostic tests. Although spray coverage remained relatively high (> 70\%) over the time period, reported net usage was generally below 40\%. Parasite prevalence reduced from 43.3 to 10.5\% between 2004 and 2016. The prevalence of moderate to severe anaemia in children aged 1-5 years reduced from 14.9 to $1.6 \%$. Impact in individual sites ranged from 57 to 100\% reductions in parasite prevalence between 2004 and 2016. Sleeping under a net and living in a house that had been sprayed in the past 12 months were independently protective against infection $(\mathrm{OR}=0.69$ [95\% $\mathrm{Cl} 0.61-0.80$ ] and $\mathrm{OR}=0.87$ [95\% Cl 0.78-0.97], respectively), whilst recent travel to the mainland increased the odds of infection nearly fourfold ( $\mathrm{OR}=3.94[95 \% \mathrm{Cl} 2.79-5.56]$ ).

Conclusion: Island-wide interventions have resulted in a substantial reduction in malaria transmission on Bioko Island. This unique time series of 13 consecutive annual malaria indicator surveys clearly demonstrates the long-term effectiveness of the sustained use of two vector control interventions, indoor residual spraying and LLINs, and the value of comprehensive and sustained surveillance. Despite considerable success in reducing the burden on the island, malaria is still endemic, with populations in some areas remaining at high risk of infection.

Keywords: Malaria, Vector control, Longitudinal, Epidemiology, Intervention, Monitoring and evaluation

\section{Background}

Despite a large scale-up in access to long-lasting insecticide-treated nets (LLIN) and indoor residual spraying (IRS), malaria remains a major public health burden across much of sub-Saharan Africa. As intervention

\footnotetext{
*Correspondence: Jackie.cook@lshtm.ac.uk

${ }^{1}$ MRC Tropical Epidemiology Group, London School of Hygiene and Tropical Medicine, London WC1E7HT, UK

Full list of author information is available at the end of the article
}

coverage increases across the continent, monitoring and evaluation of control programmes become paramount, although reliable indicators are often lacking and can be contradictory [1]. Several recent studies have used repeated community surveys to analyse long-term trends of malaria transmission in areas of declining exposure to malaria parasites [2-4]. Community surveys have advantages over passively collected data in that they are able to estimate the true prevalence within a population, 
regardless of symptoms and health-seeking behaviour. Accurately tracking changes in malaria transmission following implementation of malaria control can help to ensure that interventions are efficiently targeted.

Islands are considered ideal settings for effective malaria control due to the limited population migration and well-defined geographical borders. Several island nations have achieved substantial reductions in malaria transmission attributed to successful interventions [5-8], with Sri Lanka recently being certified malariafree [9]. Bioko Island, Equatorial Guinea, with historically high malaria transmission [10], has been subject to extensive interventions including intensive vector control, improved case management, intermittent preventative treatments (IPT) and behavioural change interventions since 2004 through the Bioko Island Malaria Control Project (BIMCP) [11]. The BIMCP is a public-private malaria control project funded by Marathon Oil, the government of Equatorial Guinea and other partners. It has been implemented by Medical Care Development International (MCDI), along with researchers and key stakeholders. Early evaluations indicated that malaria transmission had dropped considerably, resulting in a $60 \%$ reduction in child mortality following the first 4 years of interventions [12], and a corresponding 50\% drop in parasite prevalence in children aged between 1 and 14 years [13]. However, despite its island status, a study in 2013 demonstrated that travel to the mainland of Equatorial Guinea increased the risk of infection in travellers themselves, and in non-travellers living in neighbourhoods with high proportions of travellers [14], highlighting the impact of population movement on malaria transmission levels [15-18].

Malaria indicator surveys (MIS) take place annually within sentinel sites across the island as part of an enhanced monitoring and evaluation programme to assess the progress of the BIMCP towards its ultimate goal of malaria elimination. Transmission trends over more than a decade of vector control were examined using the time series of 13 consecutive cross-sectional assessments of parasitaemia and anaemia prevalence.

\section{Methods}

\section{Setting and interventions}

Bioko, the largest island of Equatorial Guinea (approximately $2000 \mathrm{~km}^{2}$ ), is $32 \mathrm{~km}$ from the coast of Cameroon. Its population, of approximately 250,000 (of which approximately $90 \%$ live in Malabo, the capital city,) are at risk of malaria year-round. Before the launch of the BIMCP in 2004, entomological inoculation rates (EIR) on the island were in excess of 750 infectious bites per person per year [10].
Island-wide Indoor Residual Spraying (IRS) was the principal intervention implemented by the BIMCP on a biannual basis beginning in 2004. The insecticide deltamethrin was used in the first year, followed by bendiocarb from 2005 to 2012, then deltamethrin again from 2013 to 2014 with a switch back to bendiocarb in 2015 and 2016. Since the switch back to bendiocarb in 2015, IRS has been targeted at particular communities rather than the whole island, as a strategy for enhancing the cost-effectiveness of vector control, taking into account variable community acceptance of the intervention after a decade of persistent spraying. Targeting was based on a risk score composed of community-level parasite prevalence, quality of housing (a measure of susceptibility to vector infiltration), risk of parasite importation as expressed by prevalence of reported travel to the mainland within the preceding 8 weeks, and previous IRS coverage (as a proxy for acceptability in the community).

A first mass distribution of long-lasting insecticidetreated nets (LLIN) was conducted on Bioko in late 2007 and early 2008, which achieved initial reported coverage of an average of three nets per household [19]. A second mass distribution of LLIN took place in late 2014 and early 2015 , reportedly reaching $87 \%$ of households (unpublished data, BIMCP).

\section{Monitoring and evaluation}

MIS have been conducted annually in August/September on Bioko since 2004. This study utilizes data from 13 surveys from 2004 through to 2016. The survey protocol has stayed broadly similar throughout this time period with the exception of the age group targeted for sampling. Between 2004 and 2007, only children aged between 1 and 14 years were sampled, with the addition of head of households between 2008 and 2012, and the inclusion of everyone present in the household from 2013 onwards.

Seventeen sentinel sites were monitored in 2004, increasing to 18 sites (with the addition of Punta Europa) from 2005 onwards (Fig. 1). The study was originally powered to detect a decline of $30 \%$ in each sentinel site between years, assuming a design effect of 2.5. In the two most recent surveys (2015 and 2016), the sampling frame switched to include all 284 communities on the island, with over-sampling in the smaller of the sentinel sites to ensure historical comparison over time. The analysis presented here is restricted to households sampled within sentinel sites to allow for assessment of longitudinal trends. Households within sentinel sites were randomly sampled using systematic sampling from a household listing. Heads of households were asked whether their house had received IRS within the previous 12 months and whether individuals in their household used a net the night prior to the survey. From 2013 onwards, data on 


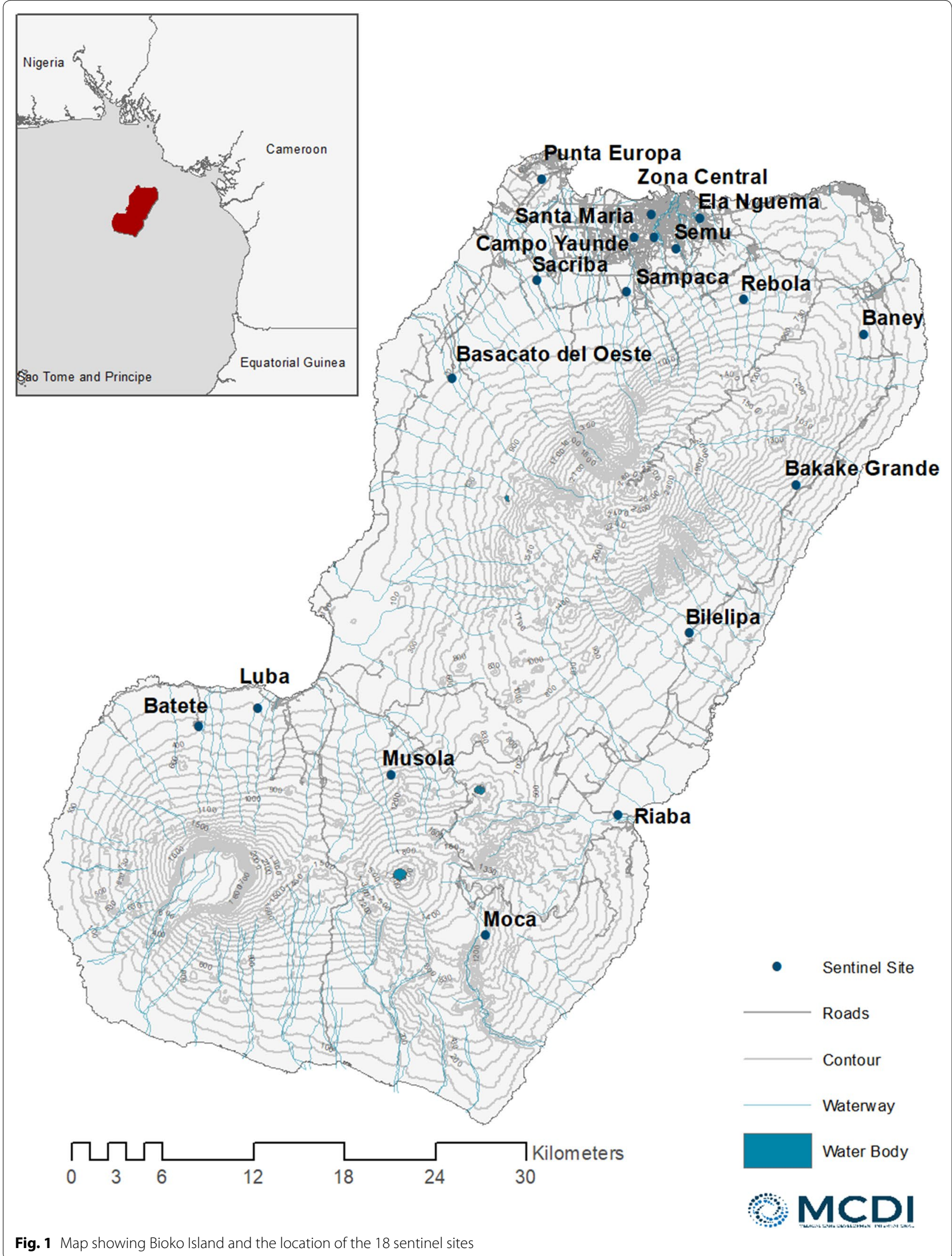


travel to mainland Equatorial Guinea within the previous 8 weeks was collected for each household member.

Haemoglobin level was measured using Haemocues (HemoCue $\mathrm{AB}$ ): mild anaemia was classified as a haemoglobin level less than $12 \mathrm{~g} / \mathrm{dl}, 11.5 \mathrm{~g} / \mathrm{dl}$ and $11 \mathrm{~g} / \mathrm{dl}$ for individuals over 12 years, between 5 and 12 years and under 5 years, respectively. Moderate to severe anaemia was classified as a haemoglobin level below $8 \mathrm{~g} / \mathrm{dl}$ for all age groups. Participants were tested for the presence of parasitaemia using a Pf/pan rapid diagnostic test (RDT) (ICT diagnostics) from 2004 to 2011 and Carestart $^{\circledR}$ RDT (Access Bio) in the later surveys. Participants testing positive were referred to a survey nurse for treatment, according to national treatment guidelines (artestunate/ amodiaquine), whilst participants with low haemoglobin levels were advised to seek care.

\section{Statistical analyses}

Due to the restricted age groups in the early surveys, only results from children aged 1-14 years are included in figures and analyses. Prevalence of infection by RDT and $95 \%$ confidence intervals were calculated for each year. The association between parasite prevalence and prevalence of moderate/severe anaemia $(<8 \mathrm{~g} / \mathrm{dl})$ in children aged 1-5 years was assessed using regression models. Differences in proportions were assessed using $\mathrm{Chi}^{2}$ tests. A logistic regression model, allowing for the survey design, was performed to estimate the mean effect of time (year; linear and categorical) on infection prevalence.

Median altitude of each sentinel site was calculated based on household global positioning system (GPS) information and sites were classified as high altitude if they were above the median altitude for all sites $(108 \mathrm{~m})$. Site-level spray coverage (based on reported spraying within sampled households) was estimated to investigate benefits of high IRS coverage at the community level. Households were classified as having universal coverage of nets if they reported having at least one net for every two people in the household. To investigate the impact of original malaria endemicity, the median baseline site prevalence $(45 \%)$ was used to stratify sites into high or moderate prevalence $(<45 \%)$.

Information about intervention coverage (net use and IRS within the last 12 months) was collected from 2006 onwards. Univariate logistic regression was used to look at the differential effects of intervention coverage on infection, comparing (1) living in a sprayed household and not using a net (2) reporting sleeping under a net and not living in a sprayed house (3) living in a sprayed house and sleeping under a net, to a baseline of no interventions. Variables that showed a crude association with RDT positivity were included in the model in a stepwise manner, including age group, original site prevalence, and site-level spray coverage. To investigate whether the switch in IRS strategy had an effect on risk factors, models were examined with and without the surveys from 2015 to 2016. A separate model including recent travel to the mainland was used for data from surveys from 2013 to 2016. For consistency, this model also only included children aged 1 to 14 years.

Sampling probabilities of children aged between 1 and 14 years in each sentinel site were computed using data from a country-wide 2015 census. Responses were weighted by the inverse of sampling probabilities to compensate for the different numbers of children tested in each survey. All models controlled for year to account for temporal variations. Standard errors were adjusted to account for correlation of responses, with sentinel site specified as the primary sampling unit (PSU) when calculating an island-wide prevalence and household when calculating sentinel site level prevalence.

\section{Results}

In the thirteen surveys between 2004 and 2016, 35,146 household visits were conducted, ranging from 1043 to 4721 households per year (Table 1). The median household size was 6, with an average of 2 children (aged between 1 and 14 years) tested per household.

Reported spray coverage ranged from 56\% (in 2015 when targeted focal IRS was introduced) to $80 \%$ (in 2005). Spray coverage varied substantially between sites. Sites in Malabo and the North West consistently did not achieve spray coverage over $80 \%$-in part due to a large proportion of refusals from homeowners. A low proportion of houses reported universal net coverage, ranging from $13 \%$ (in 2011) up to $57 \%$ and $42 \%$, following the LLIN campaigns in 2007/08 and 2014/15, respectively. In the subsequent year, following the first distribution, universal coverage had already substantially reduced (21\%) whilst coverage remained similar in the year following the second distribution (40\%). The percentage of children aged 1-14 years sleeping under a net the night before the survey was below 55\% in all survey years except in 2008 when it increased to $81 \%$ (Table 1). By 2009, usage had already decreased to $40 \%$. Utilization increased to $54 \%$ following the 2nd mass distribution in 2014/15, though it remained substantially lower than immediately after the 1 st mass distribution in $2007 / 08$. Utilization of nets was higher in houses that had universal coverage, with usage varying between $76 \%$ and $92 \%$ over the study period (Table 1). Within these households, priority for sleeping under nets appeared to be given to the youngest children, with $85 \%$ of under $5 \mathrm{~s}$ sleeping under a net, compared to $82 \%$ and $78 \%$ of $5-10$ and $10-14$ year olds, respectively $(\mathrm{p}<0.001)$. In houses without universal coverage, priority 


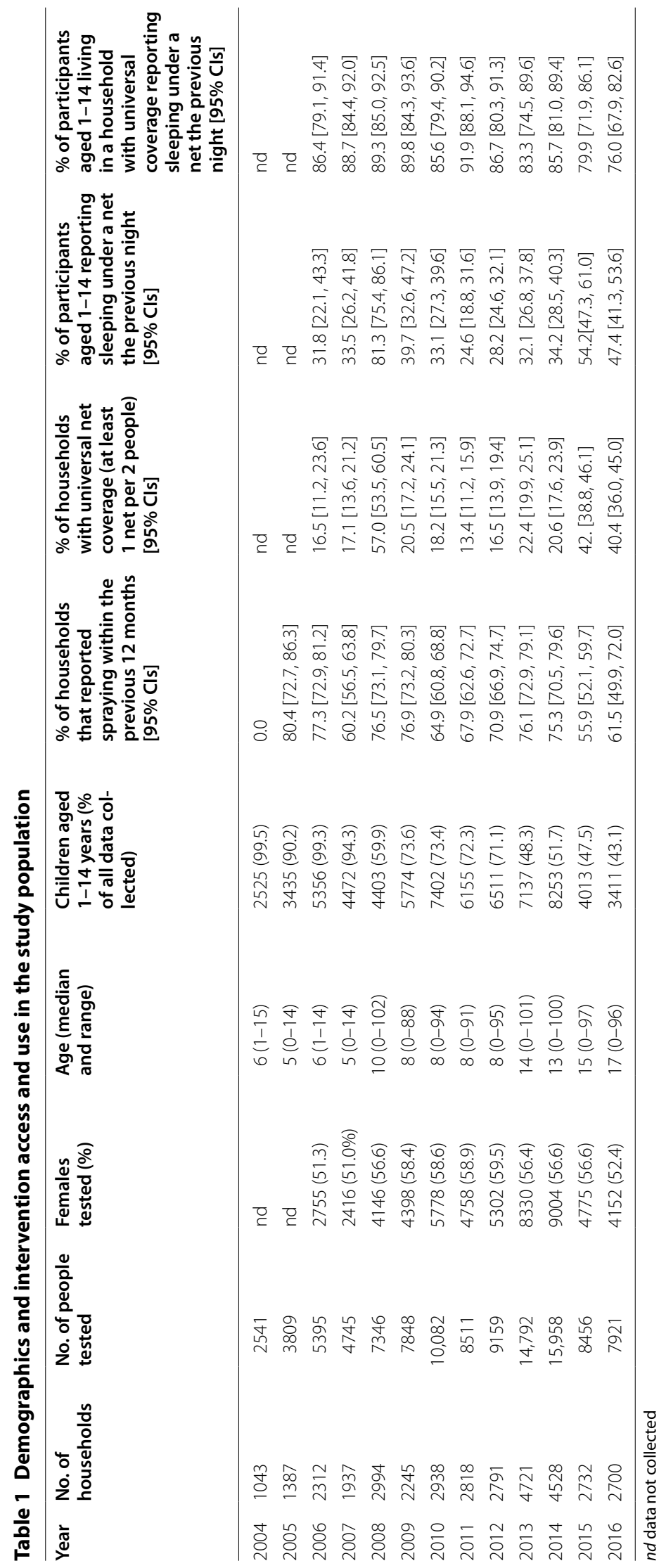


was also given to children aged between 1 and 5 years, with $30 \%$ reporting sleeping under a net, compared to only $23 \%$ and $20 \%$ of children aged $5-10$ and $10-14$, respectively ( $\mathrm{p}<0.001)$. In participants over the age of 14 years, $27 \%$ reported using a net in households without universal coverage, compared to $78 \%$ in households with universal coverage.

\section{Prevalence of parasitaemia}

Island-wide $P$. falciparum prevalence, detected by RDT, decreased by over $75 \%$ between 2004 and 2016, from $43.3 \%$ (95\%CI $37.5-49.3 \%)$ to $10.5 \%(8.8-12.5)$ ( $<<0.001)$ (Table 2). On average, there was an $11 \%$ decrease in the odds of infection per year (OR 0.89 (0.87-0.90), $\mathrm{p}<0.001)$. However, the decrease was not uniform, with similarly steep reductions seen in the first year following the implementation of interventions (2005 OR 0.55 (0.44-0.70) (compared to 2004) and in 2014 (OR 0.54 (0.43-0.68) compared to 2013) (Table 2). Several years saw no change in prevalence from the previous year $(2007,2009,2010)$ whilst in 2013 there was a notable increase in prevalence.

Plasmodium falciparum prevalence decreased across all age groups over the study period (see Additional file 1). Children aged 5-14 years were consistently most likely to be infected. In 2004, the burden fell primarily on 5 to 10 year olds, but by 2016, this had shifted to 10-14 year olds. From 2013 onwards, participants aged 15-25 years were also at higher risk than under 5s (ORs ranging from 1.3 to 1.7 ).

\section{Prevalence of anaemia}

Prevalence of moderate/severe anaemia (haemoglobin $<8 \mathrm{~g} / \mathrm{dl}$ ) in children aged 1 to 5 years dropped by nearly 90\% between 2004 and 2016 (15-2\%) (Table 2). All sites apart from Rebola achieved at least a $75 \%$ reduction in the prevalence of anaemia, with several sites recording no cases of severe anaemia in under-fives tested in 2016. In Rebola, anaemia increased from $2.5 \%$ in 2004 to $4.7 \%$ in 2016.

Approximately $12 \%$ of children aged $1-5$ who were parasite positive had moderate/severe malaria, compared to $2 \%$ who were not parasite positive $(\mathrm{p}<0.001)$. Site-level anaemia prevalence was strongly correlated with parasite prevalence (Fig. 2).

\section{Heterogeneity of intervention effects}

Whilst prevalence of infection reduced over time, there were differences between sites (Fig. 3) and heterogeneity in the reduction of transmission over the 13 surveys (Figs. 4, 5). The biggest reductions between 2004 and 2016 were seen in Baney, where parasite prevalence was 0\% in 2016 (compared to 40\% in 2004), Rebola (a
99\% decrease since 2004) and Bilelipa (a 98\% decrease). The smallest reductions were seen in Sacriba and Central (57\% decrease since 2004) and Punta Europa (61\% decrease (since 2005)). However, all three sites had recorded lower prevalence in 2012, which subsequently rebounded. For instance, in Sacriba in 2012, prevalence had decreased by $76 \%$ since 2004 , but these gains were lost in 2013 when prevalence rebounded from 14 to $37 \%$ (Figs. 3, 4, 5). Sites in rural areas recorded more substantial reductions in prevalence between 2004 and 2016 than sites in urban areas (79.0\% vs. $74.1 \%$ ).

The 3 sites which had achieved highest impact were compared to those that had achieved the least impact to establish whether there were key differences. Participants who lived in the sites with the highest impact were less likely to have travelled $(2.3 \%$ vs. $9.2 \%, \mathrm{p}=0.01)$ and were more likely to live in sprayed households $(79.7 \%$ vs. $67.5 \%, \mathrm{p}=0.037)$. Net use and access was similar in all six sites. Sites with highest impact had median altitudes over $200 \mathrm{~m}$ whilst lowest impact sites all had median altitudes lower than $55 \mathrm{~m}$. Two out of three sites with the highest impact were classified as moderate prevalence pre-intervention (Baney and Rebola), whilst only one of the least impact was classed as moderate prevalence (Central).

In 2016, 9 of the 18 sentinel sites had prevalences below 10\%: this included all sites in the North East, South West and Highland regions of the island. No sites in the North West region (Basacato, Punta Europa, Sacriba and Sampaka) had parasite prevalences under 10\% (Fig. 5).

\section{Risk factors for parasite positivity}

There was no evidence for risk factors varying substantially between years. There was not strong evidence that living in a site with high spray coverage (> 80\%) or in a site with higher altitude was associated with lower infection prevalence (Table 3). The association between spray coverage and infection prevalence remained even when 2015 and 2016 (when spraying was targeted) were removed from the analysis. The final model included age group, pre-intervention site prevalence, and vector control usage. Under $5 \mathrm{~s}$, living a site with lower initial prevalence, and net use in a recently sprayed house were all associated with lower odds of infection (Table 3). Sleeping under a net reduced the odds of infection by a quarter [OR $0.75(0.63-0.88)$ ] whilst sleeping in a recently sprayed house reduced the odds by $14 \%$ [OR $0.86(0.77-$ $0.96)$ ], compared to no interventions. There was an additive effect of the two interventions [OR $0.58(0.53-63)$ ] and no evidence of interaction between the two interventions $(\mathrm{p}=0.178)$.

The influence of recent travel to the mainland was examined for surveys where data was collected 


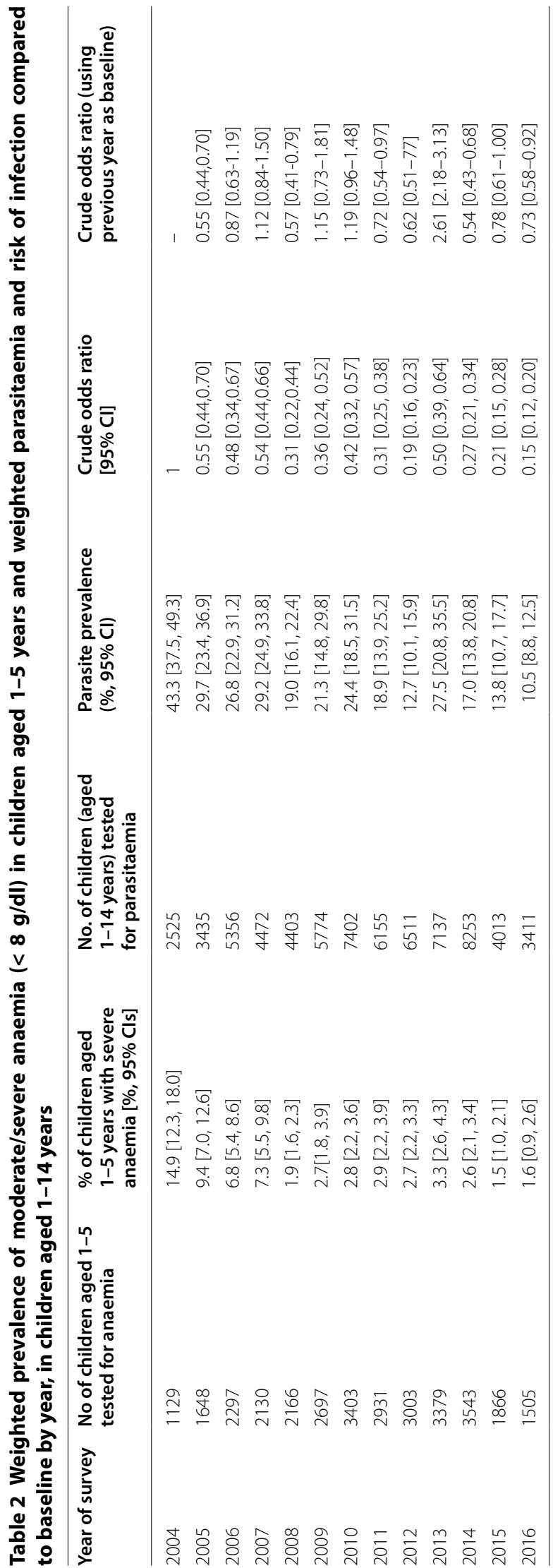




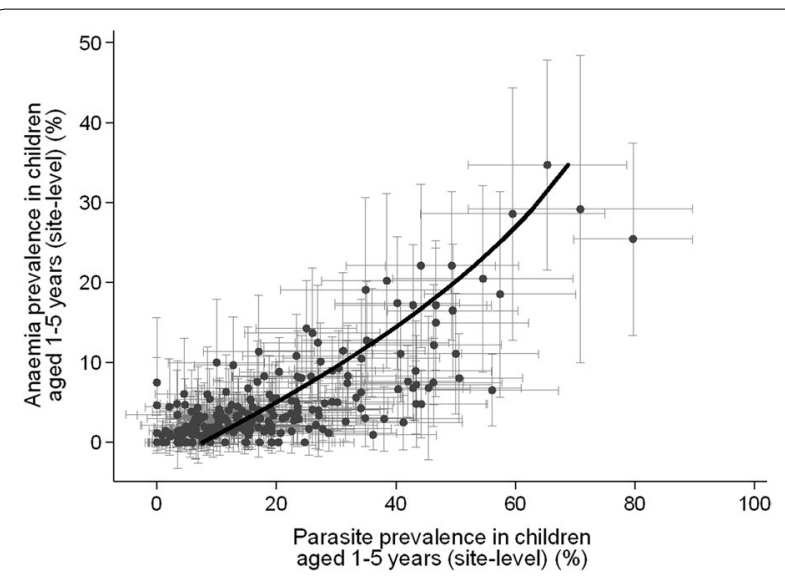

Fig. 2 Correlation between site level prevalence of severe anaemia $(<8 \mathrm{~g} / \mathrm{dl})$ and parasite prevalence in children aged between 1 and 5 years, with $95 \%$ confidence intervals. The data is overlaid with a quadratic fit, indicating that parasite prevalence increases by $2.5 \%$ $(1.8-3.3 \%)$ for every $1 \%$ increase in anaemia, with the slope decreasing by $0.04 \%$ for every $1 \%$ increase

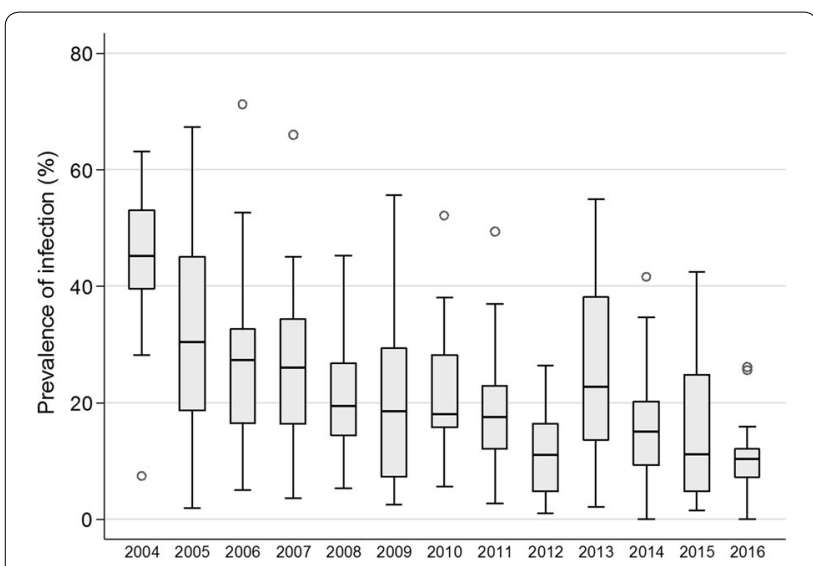

Fig. 3 Box and whisker plot highlighting site-level parasite prevalence in children aged 1-14 years by year. The mid-line in the box represents the median prevalence across all sites

(2013-2016). The proportion of participants reporting travel was relatively small, ranging from 6\% in 2013 and 2014 , up to $10 \%$ in 2016 , but with wide variation between sites. Travellers were more likely to be women and to be aged between 15 and 50 years. The proportion of people travelling was highest in sites in Malabo, increasing from 9\% in 2013 to $14 \%$ in 2016. Infection was higher in people reporting recent travel than those who had not travelled (30.1\% vs. $12 \%, \mathrm{p}<0.001)$. Before adjusting for other risk factors, travel to the mainland increased the odds of infection in children aged 1-14 nearly 4-fold (OR 3.6 $(2.6-5.1, \mathrm{p}<0.001))$. When incorporated with the other risk factors in the final model, travel to the mainland remained strongly associated with infection (OR 3.4 $(2.5-4.6, \mathrm{p}<0.001))$.

\section{Discussion}

Monitoring and evaluation play a key role in malaria control campaigns and are essential for assessing the impact of interventions and guiding programmes in adapting operational approaches. The World Health Organization (WHO) Global Technical Strategy [20] emphasizes surveillance as a core intervention for reducing malaria burden and achieving elimination. On Bioko, comprehensive surveillance through annual MIS have allowed for detailed examination of the impact of interventions and control strategies.

The BIMCP has been an overall success, achieving a reduction in parasitaemia of over $75 \%$ over 13 years. In the early years of implementation, there was heterogeneity of impact between sites. Differential impact of universal interventions have been documented in other studies $[4,21]$ and has been attributed in part to uneven distribution or uptake of interventions [11, 22], which was seen on Bioko with varying coverage of IRS and use of LLINs. There was evidence that living in a site that had initial high prevalence resulted in a higher risk of infection overall, although, this was not universally true, with Bilelipa (with a pre-intervention prevalence of 49\%) recording a $97 \%$ reduction in prevalence by 2016 , whilst Central (pre-intervention prevalence of $28 \%$ ) achieved a more modest $57 \%$ reduction. More notable was the difference in reduction by region with the North Eastern sites (Bakake Grande, Baney, Rebola) showing an average decrease of $94 \%$ compared to an average decrease of $65 \%$ in the North West (Basacato, Punta Europa, Sacriba, Sampaka). In Punta Europa, a site which consistently showed higher prevalence, this was attributed initially to low IRS coverage with infection prevalence decreasing once IRS coverage increased.

The main preventative intervention employed on Bioko is IRS. Whilst IRS can protect the sprayed household through a repellent effect (depending on the insecticide used), its main effect is through killing action resulting in community-wide protection when a sufficiently high spray coverage is reached [23]. The WHO recommends that $>80 \%$ of structures need to be sprayed for IRS to have a community effect [24]. In this study, living in a site with spray coverage over $80 \%$ resulted in lower risk of infection but the association was not significant. A previous study collating data from Equatorial Guinea and Malawi demonstrated that higher spray coverage resulted in decreased infection prevalence [19].

In addition to IRS, two mass LLIN distributions took place; however, MIS which took place within 6 months 


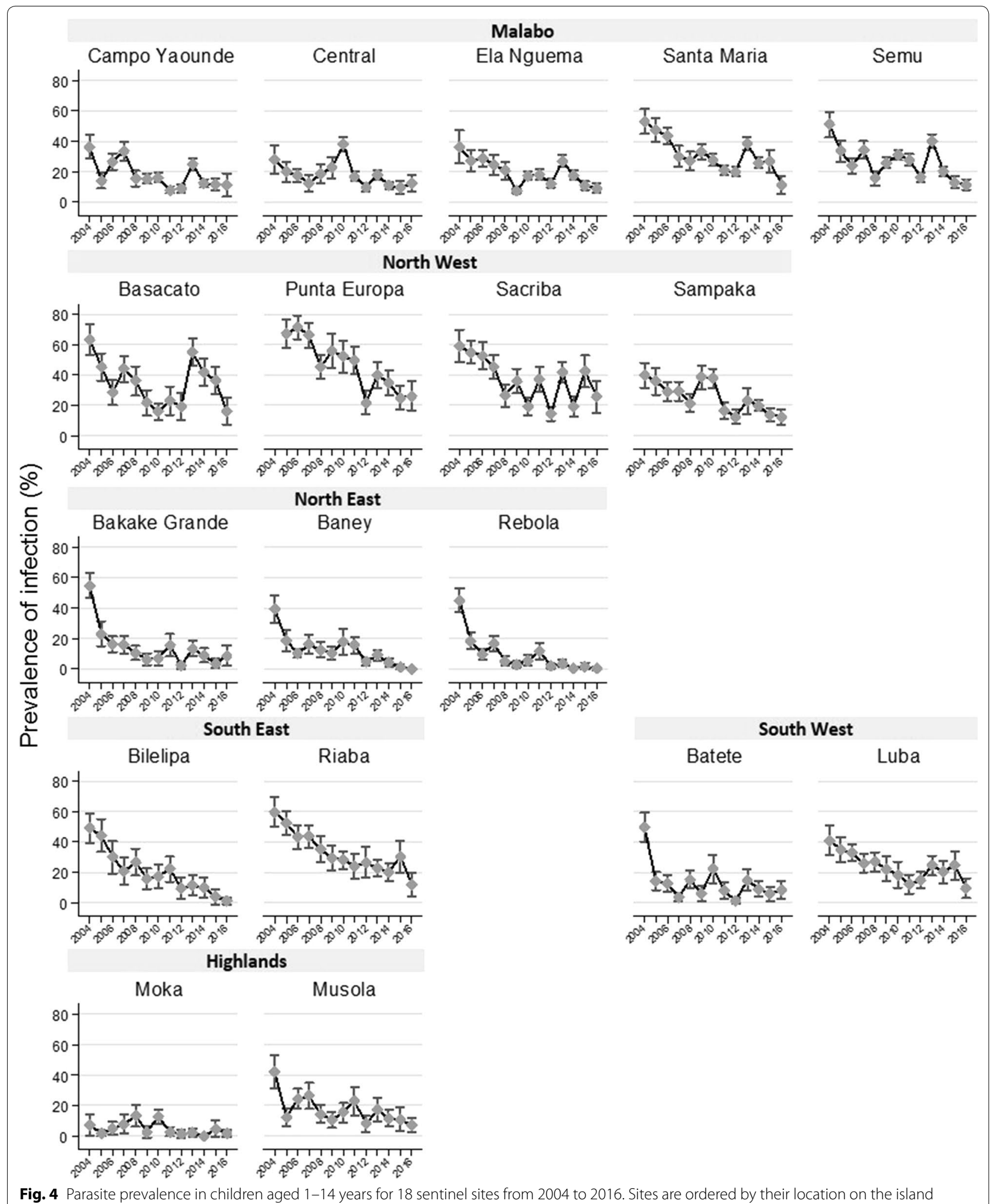




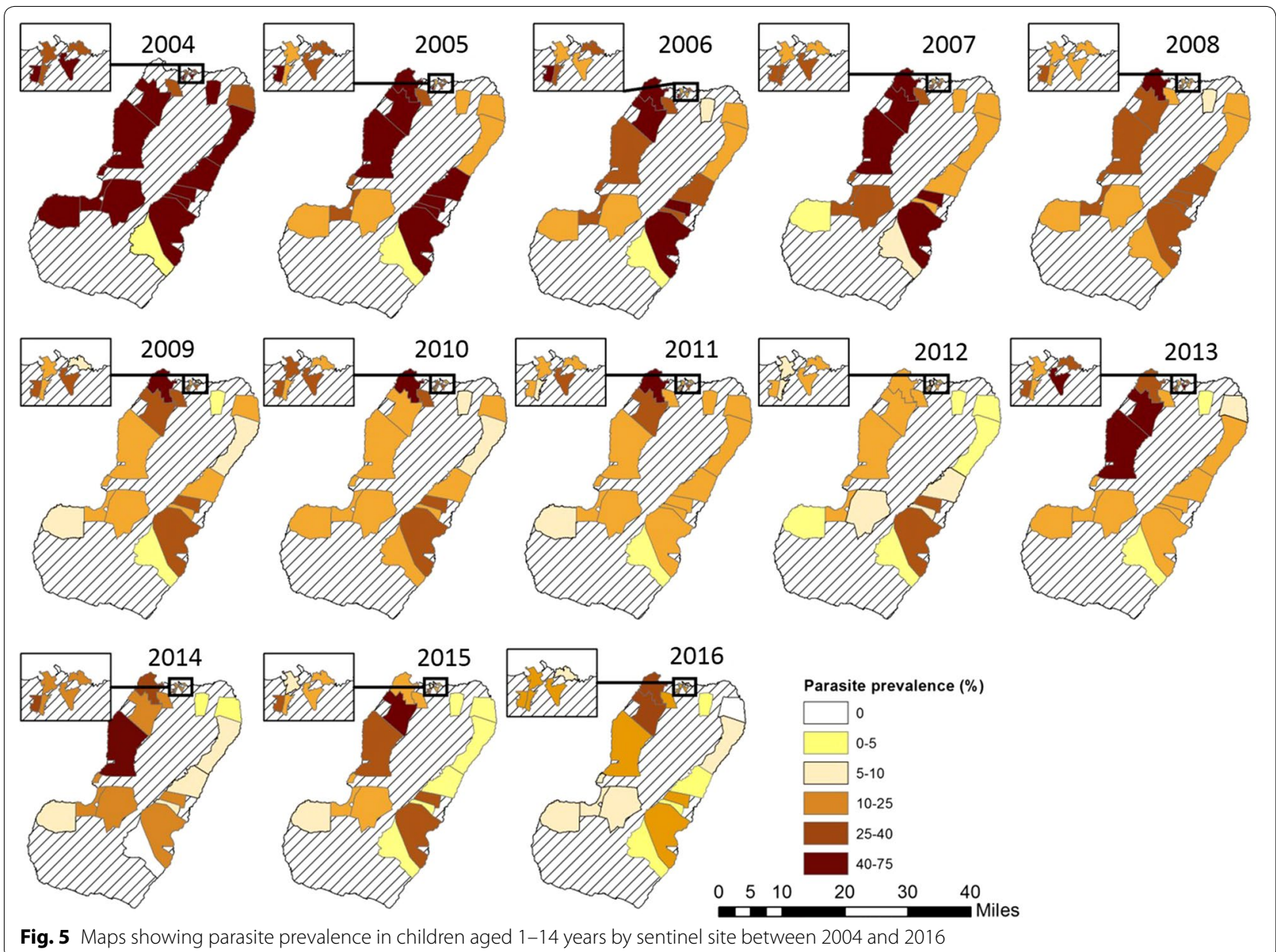

of the distributions suggest that if high coverage was originally achieved, it had quickly reduced. This may be because some of the nets that were distributed were subsequently taken to the mainland where little malaria control is in place and malaria transmission is substantially higher. Studies are ongoing to establish why attrition of nets was so high. In households with universal coverage, the use of nets was high, indicating that the barrier to higher LLIN utilization is the lack of access to nets, not unwillingness to use them.

Net use was shown to be protective against infection, with children reporting sleeping under a net the previous night (and not living in a sprayed house) having 30\% lower odds of being infected. A treated net provides a physical barrier against biting mosquitoes and protection through reduction of the mosquito population by insecticidal action. Several sites saw steep falls in parasite prevalence between 2007 and 2008, which may have been due to increased net use. The proportion of people with access to nets post-2008 reduced to approximately
$20 \%$, but despite this, there was no sign of a rebound in malaria prevalence (or severe anaemia), suggesting other factors were also contributing to maintenance of the new lower equilibrium. The highest infection prevalence was consistently detected in children aged between 5 and 14 years old, who were also least likely to be using a net.

IRS and LLIN are often used in combination rather than alone. As with previous studies in Equatorial Guinea $[25,26]$, and elsewhere $[27,28]$, this study demonstrated an additive effect of the combination of both interventions. The effect of the combination of the two interventions is likely to depend on intervention coverage, initial transmission levels, the insecticides used, and on the local vector population [29-31].

In recent years, population movement to the mainland of the country increased, perhaps due to more transport options, or an overall increase in wealth. Travel to the mainland, where malaria is higher [26], has been shown to be a risk factor for infection on Bioko previously [14]. More people reported travel in the three sites 
Table 3 Risk factors for $P$. falciparum infection in children aged 1 to 14 years from 13 years of survey data

\begin{tabular}{|c|c|c|c|c|c|c|c|}
\hline Risk factors & $\begin{array}{l}\% \text { RDT posi- } \\
\text { tive (N) }\end{array}$ & $\begin{array}{l}\text { Odds } \\
\text { ratios } \\
(\text { OR) }\end{array}$ & $95 \% \mathrm{Cl}$ & $p$ value & $\begin{array}{l}\text { Adjusted Odds } \\
\text { Ratios (aOR) }\end{array}$ & $95 \% \mathrm{Cl}$ & p value \\
\hline \multicolumn{8}{|l|}{ Intervention use } \\
\hline No intervention & $24.4 \%(13,871)$ & 1 & & & 1 & & $p<0.001$ \\
\hline Sleeping under a net & $17.6 \%(4826)$ & 0.69 & $(0.61-0.80)$ & $p<0.001$ & 0.75 & $(0.63-0.88)$ & \\
\hline Sleeping in a sprayed house & $22.1 \%(26,351)$ & 0.87 & $(0.78-0.97)$ & & 0.86 & $(0.77-0.96)$ & \\
\hline Slept under a net and sleeping in a sprayed house & $15.7 \%(14,867)$ & 0.57 & $(0.52-0.63)$ & & 0.58 & $(0.53-0.63)$ & \\
\hline \multicolumn{8}{|l|}{ Age group } \\
\hline $1-5$ years & $20.8 \%(32,077)$ & 1 & & $p<0.001$ & 1 & & $p<0.001$ \\
\hline $5-10$ years & $28.9 \%(22,952)$ & 1.59 & $(1.43-1.78)$ & & 1.70 & $1.60-1.80$ & \\
\hline 10-14 years & $29.9 \%(13,818)$ & 1.67 & $(1.53-1.84)$ & & 1.95 & $1.78-2.11$ & \\
\hline \multicolumn{8}{|l|}{ Site location } \\
\hline Living in an urban site & $21.3 \%(35,141)$ & 1 & & & & & \\
\hline Living in a rural site & $21.6 \%(33,706)$ & 1.0 & $(0.65-1.54)$ & 0.962 & & & \\
\hline \multicolumn{8}{|l|}{ Spray coverage } \\
\hline Living in a site with spray coverage $<80 \%$ & $26.4 \%(50,754)$ & 1 & & & & & \\
\hline Living in a site with spray coverage $\geq 80 \%$ & $19.9 \%(18,093)$ & 0.74 & $(0.46-1.2)$ & $p=0.214$ & & & \\
\hline \multicolumn{8}{|l|}{ Site altitude } \\
\hline Living in a site with median altitude < $108 \mathrm{~m}$ & $23.9 \%(45,407)$ & 1 & & & & & \\
\hline Living in a site with median altitude $\leq 108 \mathrm{~m}$ & $16.7 \%(23,482)$ & 0.79 & $(0.47-1.3)$ & 0.345 & & & \\
\hline \multicolumn{8}{|l|}{ Previous transmission level } \\
\hline Living in a site with low prevalence in $2004(<45 \%)$ & $21.4 \%(39,016)$ & 1 & & & 1 & & \\
\hline $\begin{array}{l}\text { Living in a site with high prevalence in } 2004 \\
(>45 \%)\end{array}$ & $31.3 \%(29,831)$ & 1.72 & $(1.31-2.26)$ & $p<0.001$ & 1.66 & $1.22-2.26$ & 0.003 \\
\hline
\end{tabular}

adjusted for survey year

b Adjusted for age group, original site prevalence and year

demonstrating the least impact, compared to the three with the highest impact, further highlighting the importance of this risk factor. Infection importation remains a persistent and significant challenge for malaria control on Bioko and a potential barrier to further reduction of transmission on the island. Despite being an island, population travel to and from higher risk areas makes Bioko vulnerable to importation of infection. Border screening and treatment, targeted 'Malaria Awareness' campaigns or chemoprophylaxis may help to alleviate this issue. Expansion of control activities to include the mainland area of Equatorial Guinea are likely to have an additional impact.

Whilst interventions have reduced the risk of infection, substantial variation in transmission over the study period remains unexplained. A factor which may have resulted in reduced transmission over time is an increase in the quality of housing, which has been shown in Bioko [32], and elsewhere, to be associated with lower malaria incidence [33, 34]. Bioko has seen improvements in socio-economic status during the project timeline which has probably also contributed to a reduction in overall transmission. In addition, access to free treatment with artemisinin-based combination therapy was introduced in 2005 and provision of drugs through private vendors has also increased over the study period. A reason for the differential impact could be due to population behaviour, such as population movement between higher and lower transmission areas or increasing outdoor behaviour in the evenings due to the provision of electricity and lighting resulting in heightened exposure to outdoor biting. Data collected several years ago on Bioko suggested that outdoor biting was not associated with malaria infection at the time, mainly because peak biting occurs at a time when most people are indoors [35]. However, as human behaviour changes, outdoor biting may become a significant risk for infection.

Although there has been a decrease in prevalence in most years of the project, 2013 stood out as an anomaly, when prevalence increased in most sites, following a particularly low prevalence recorded in 2012. This may have been influenced by the choice of insecticide used that year. In 2004, the insecticide used for spraying was switched from deltamethrin to bendiocarb following the detection of the $k d r$ mutation in the Anopheles gambiae population [36]. Subsequent analysis showed that despite 
the presence of $k d r$, the 2004 pyrethroid spray round nevertheless resulted in a sharp reduction in sporozoite infectivity in the main vector after spraying, and there was no apparent association between $k d r$ and phenotypic resistance. In 2013 deltamethrin spraying was re-introduced as part of a programme of insecticide resistance management through rotation [37]. Following the change back, a sharp increase in parasite prevalence was recorded in the subsequent household survey of 2013, despite no obvious decrease in intervention coverage, prompting fears of resistance of local vectors to deltamethrin [38]. The presence of resistance markers is currently being monitored across the island.

Despite the heterogeneous impact of interventions in Bioko, transmission has declined substantially overall. Understanding the factors that have contributed to differential impact will help the BIMCP to prioritize strategies and to continue the downward trajectory in parasite rate. Indeed, several areas, which have now reached pre-elimination levels, are now implementing further strategies, such as reactive case detection, to attempt elimination of local transmission. This study has shown that vector control with IRS and LLINs remained the most important protective intervention on Bioko, whilst travel to the mainland constituted a substantial risk for malaria infection. The low proportion of houses with universal coverage of LLINs, and data suggesting that the age group most likely to be infected are least likely to be using a net (10$14 \mathrm{yr}$ olds) is concerning. Strategies to ensure a higher proportion of the population have access to nets have been implemented, but the lack of LLINs on the mainland and the high rate of associated leakage of nets, may have undermined the ability to maintain high coverage levels. Controlling parasite importation from the mainland, and maintaining universal access to the core prevention, namely LLIN use, represent two clear challenges to further reducing malaria transmission on Bioko.

Whilst the gains over the past 13 years have been impressive, the slow, but steady progress highlights the importance of sustaining malaria control interventions on a long-haul basis. Long-term commitment and surveillance are necessary to chart the downward trend which may not necessarily advance in an uninterrupted linear manner.

\section{Additional file}

Additional file 1: Figure S1. Parasite prevalence and 95\% confidence intervals by year of age between 2004 and 2016.

\section{Authors' contributions}

JC, DH, WP, JB, LS, GG, CS and IK designed the study. DH, WP, LS, MR and GG implemented the study. JC, JB and IK analysed the data. JC and IK wrote the paper. All authors read and approved the final manuscript.

\begin{abstract}
Author details
${ }^{1}$ MRC Tropical Epidemiology Group, London School of Hygiene and Tropical Medicine, London WC1E7HT, UK. ${ }^{2}$ Medical Care Development International, Silver Spring, MD, USA. ${ }^{3}$ Bioko Island Malaria Control Project, Medical Care Development International, Malabo, Equatorial Guinea. ${ }^{4}$ Equatorial Guinea Ministry of Health and Social Welfare, Malabo, Equatorial Guinea. ${ }^{5}$ School of Pathology, Faculty of Health Sciences, University of Witwatersrand, Johannesburg, South Africa.
\end{abstract}

\section{Acknowledgements}

We thank the participants on Bioko Island who have taken part in the surveys since the inception of the project. We would also like to thank Giovanna Baltazar and Andrea Rehman who have assisted with survey implementation and data analysis over the period of the study.

\section{Competing interests}

The authors declare that they have no competing interests.

\section{Availability of data and materials}

The datasets used and/or analysed during the current study are available from the corresponding author on reasonable request.

\section{Consent for publication}

Not applicable.

\section{Ethics approval and consent to participate}

Ethics approval for the study was granted by the Equatorial Guinea Ministry of Health and Social Welfare and the ethics committee of the London School of Hygiene and Tropical Medicine (approval number 5556). Written informed consent was sought from each participating adult and on behalf of participating children.

\section{Funding}

This work was funded by the Government of Equatorial Guinea and a consortium of private donors led by Marathon Oil Corporation.

\section{Publisher's Note}

Springer Nature remains neutral with regard to jurisdictional claims in published maps and institutional affiliations.

Received: 12 December 2017 Accepted: 30 January 2018

Published online: 05 February 2018

References

1. Tusting LS, Bousema T, Smith DL, Drakeley C. Measuring changes in Plasmodium falciparum transmission: precision, accuracy and costs of metrics. Adv Parasitol. 2014;84:151-208.

2. Trape JF, Tall A, Sokhna C, Ly AB, Diagne N, Ndiath O, et al. The rise and fall of malaria in a West African rural community, Dielmo, Senegal, from 1990 to 2012: a 22 year longitudinal study. Lancet Infect Dis. 2014;14:476-88.

3. Farnert A, Yman V, Homann MV, Wandell G, Mhoja L, Johansson M, et al. Epidemiology of malaria in a village in the Rufiji River Delta, Tanzania: declining transmission over 25 years revealed by different parasitological metrics. Malar J. 2014;13:459.

4. De Beaudrap P, Nabasumba C, Grandesso F, Turyakira E, Schramm B, Boum $Y$ 2nd, et al. Heterogeneous decrease in malaria prevalence in children over a six-year period in south-western Uganda. Malar J. 2011;10:132.

5. Bhattarai A, Ali AS, Kachur SP, Martensson A, Abbas AK, Khatib R, et al. Impact of artemisinin-based combination therapy and insecticidetreated nets on malaria burden in Zanzibar. PLoS Med. 2007;4:e309.

6. Teklehaimanot HD, Teklehaimanot A, Kiszewski A, Rampao HS, Sachs JD. Malaria in Sao Tome and principe: on the brink of elimination after three years of effective antimalarial measures. Am J Trop Med Hyg. 2009;80:133-40.

7. Kaneko A, Taleo G, Kalkoa M, Yamar S, Kobayakawa T, Bjorkman A. Malaria eradication on islands. Lancet. 2000;356:1560-4. 
8. Kassim SA, James PB, Alolga RN, Assanhou AG, Kassim SM, Bacar A, et al. Major decline in malaria morbidity and mortality in the Union of Comoros between 2010 and 2014: the effect of a combination of prevention and control measures. S Afr Med J. 2016;106:709-14.

9. WHO. Maintaining momentum in Sri Lanka to ensure that malaria is gone - but not forgotten. WHO South East Asia J Public Health. 2016;5:79-81.

10. Cano J, Berzosa PJ, Roche J, Rubio JM, Moyano E, Guerra-Neira A, et al. Malaria vectors in the Bioko Island (Equatorial Guinea): estimation of vector dynamics and transmission intensities. J Med Entomol. 2004;41:158-61.

11. Kleinschmidt I, Torrez M, Schwabe C, Benavente L, Seocharan I, Jituboh $D$, et al. Factors influencing the effectiveness of malaria control in Bioko Island, equatorial Guinea. Am J Trop Med Hyg. 2007;76:1027-32.

12. Kleinschmidt I, Schwabe C, Benavente L, Torrez M, Ridl FC, Segura JL, et al. Marked increase in child survival after four years of intensive malaria control. Am J Trop Med Hyg. 2009;80:882-8.

13. Cook J, Kleinschmidt I, Schwabe C, Nseng G, Bousema T, Corran PH, et al. Serological markers suggest heterogeneity of effectiveness of malaria control interventions on Bioko Island, equatorial Guinea. PLoS ONE. 2011;6:e25137.

14. Bradley J, Monti F, Rehman AM, Schwabe C, Vargas D, Garcia G, et al. Infection importation: a key challenge to malaria elimination on Bioko Island Equatorial Guinea. Malar J. 2015;14:46.

15. Means SA, Smith RJ. The impact of human and vector distributions on the spatial prevalence of malaria in sub-Saharan Africa. J Theor Biol. 2016:409:70-85

16. Pindolia DK, Garcia AJ, Wesolowski A, Smith DL, Buckee CO, Noor AM, et al. Human movement data for malaria control and elimination strategic planning. Malar J. 2012;11:205.

17. Stoddard ST, Morrison AC, Vazquez-Prokopec GM, Paz Soldan V, Kochel $\mathrm{TJ}$, Kitron $\mathrm{U}$, et al. The role of human movement in the transmission of vector-borne pathogens. PLoS Negl Trop Dis. 2009;3:e481.

18. Wesolowski A, Eagle N, Tatem AJ, Smith DL, Noor AM, Snow RW et al. Quantifying the impact of human mobility on malaria. Science 2012;338:267-70.

19. Rehman AM, Coleman M, Schwabe C, Baltazar G, Matias A, Gomes IR, et al. How much does malaria vector control quality matter: the epidemiological impact of holed nets and inadequate indoor residual spraying. PLOS ONE. 2011;6:e19205.

20. WHO. Global Technical Strategy for Malaria 2016-2030. Geneva: World Health Organization; 2016.

21. ClarkTD, Greenhouse B, Njama-Meya D, Nzarubara B, Maiteki-Sebuguzi C, Staedke SG, et al. Factors determining the heterogeneity of malaria incidence in children in Kampala, Uganda. J Infect Dis. 2008;198:393-400.

22. Barat LM, Palmer N, Basu S, Worrall E, Hanson K, Mills A. Do malaria control interventions reach the poor? A view through the equity lens. Am J Trop Med Hyg. 2004;71:174-8.

23. Zhou G, Githeko AK, Minakawa N, Yan G. Community-wide benefits of targeted indoor residual spray for malaria control in the western Kenya highland. Malar J. 2010;9:67.

24. WHO. Indoor residual spraying: an operational manual for IRS for malaria transmission control and elimination. World Health Organization; 2015.

25. Kleinschmidt I, Schwabe C, Shiva M, Segura JL, Sima V, Mabunda SJ, et al. Combining indoor residual spraying and insecticide-treated net interventions. Am J Trop Med Hyg. 2009;81:519-24.
26. Rehman AM, Mann AG, Schwabe C, Reddy MR, Roncon Gomes I, Slotman $M A$, et al. Five years of malaria control in the continental region, Equatorial Guinea. Malar J. 2013;12:154.

27. West PA, Protopopoff N, Wright A, Kivaju Z, Tigererwa R, Mosha FW, et al. Indoor residual spraying in combination with insecticide-treated nets compared to insecticide-treated nets alone for protection against malaria: a cluster randomised trial in Tanzania. PLoS Med. 2014;11:e1001630.

28. Fullman N, Burstein R, Lim SS, Medlin C, Gakidou E. Nets, spray or both? The effectiveness of insecticide-treated nets and indoor residual spraying in reducing malaria morbidity and child mortality in sub-Saharan Africa. Malar J. 2013;12:62.

29. Lines J, Kleinschmidt I. Is malaria control better with both treated nets and spraying? Lancet. 2015;385:1375-7.

30. Okumu FO, Moore SJ. Combining indoor residual spraying and insecticide-treated nets for malaria control in Africa: a review of possible outcomes and an outline of suggestions for the future. Malar J. 2011;10:208

31. West PA, Protopopoff N, Wright A, Kivaju Z, Tigererwa R, Mosha FW, et al. Enhanced protection against malaria by indoor residual spraying in addition to insecticide treated nets: is it dependent on transmission intensity or net usage? PLOS ONE. 2015;10:e0115661.

32. Bradley J, Rehman AM, Schwabe C, Vargas D, Monti F, Ela C, et al. Reduced prevalence of malaria infection in children living in houses with window screening or closed eaves on Bioko Island, Equatorial Guinea. PLoS ONE. 2013;8:e80626.

33. Wanzirah H, Tusting LS, Arinaitwe E, Katureebe A, Maxwell K, Rek J, et al. Mind the gap: house structure and the risk of malaria in Uganda. PLoS ONE. 2015;10:e0117396.

34. Tusting LS, Ippolito MM, Willey BA, Kleinschmidt I, Dorsey G, Gosling RD, et al. The evidence for improving housing to reduce malaria: a systematic review and meta-analysis. Malar J. 2015;14:209.

35. Bradley J, Lines J, Fuseini G, Schwabe C, Monti F, Slotman M, et al. Outdoor biting by Anopheles mosquitoes on Bioko Island does not currently impact on malaria control. Malar J. 2015;14:170.

36. Sharp BL, Ridl FC, Govender D, Kuklinski J, Kleinschmidt I. Malaria vector control by indoor residual insecticide spraying on the tropical island of Bioko, Equatorial Guinea. Malar J. 2007;6:52.

37. Hemingway J, Vontas J, Poupardin R, Raman J, Lines J, Schwabe C, et al. Country-level operational implementation of the Global Plan for Insecticide Resistance Management. Proc Natl Acad Sci USA. 2013;110:9397-402.

38. Bradley J, Hergott D, Garcia G, Lines J, Cook J, Slotman MA, WP Phiri, et al. A cluster randomized trial comparing deltamethrin and bendiocarb as insecticides for indoor residual spraying to control malaria on Bioko Island, Equatorial Guinea. Malar J. 2016;15:378.

\section{Submit your next manuscript to BioMed Central and we will help you at every step:}

- We accept pre-submission inquiries

- Our selector tool helps you to find the most relevant journal

- We provide round the clock customer support

- Convenient online submission

- Thorough peer review

- Inclusion in PubMed and all major indexing services

- Maximum visibility for your research

Submit your manuscript at www.biomedcentral.com/submit 